Archived version from NCDOCKS Institutional Repository http://libres.uncg.edu/ir/asu/

\title{
Appalachïan
}

B O O N E, N O R T H C A R O L I N A

\section{"Woulda, Coulda, Shoulda": A Conceptual Examination Of The Sources Of Postpurchase Regret}

\author{
By: Neel Das and Anthony H. Kerr
}

\begin{abstract}
Regret is a key negative emotion consumers attempt to avoid while making decisions. Marketing researchers agree that, in addition to assessments of satisfaction, regret better explains postchoice valuation. Extant regret research in marketing literature has examined regret arising from the perspective of either the product choice or from the decision-making process that led to the purchase decision. This theoretical study examines the notion of regret arising simultaneously from both the product purchased and the decision-making process. A conceptual model is developed indicating two key moderators likely to impact the recognition and evaluation processes of the sources of regret.
\end{abstract}

Das, Neel, and Anthony H. Kerr. "WOULDA, COULDA, SHOULDA': A CONCEPTUAL EXAMINATION OF THE SOURCES OF POSTPURCHASE REGRET." Journal of Marketing Theory and Practice, vol. 18, no. 2, 2010 , pp. 171-180., www.jstor.org/stable/27821050. Publisher version of record available at: https://www.jstor.org/ stable/27821050?seq=1\#metadata_info_tab_contents 


\title{
"WOULDA, COULDA, SHOULDA": A CONCEPTUAL EXAMINATION OF THE SOURCES OF POSTPURCHASE REGRET
}

\author{
Neel Das and Anthony H. Kerr
}

\begin{abstract}
Regret is a key negative emotion consumers attempt to avoid while making decisions. Marketing researchers agree that, in addition to assessments of satisfaction, regret better explains postchoice valuation. Extant regret research in marketing literature has examined regret arising from the perspective of either the product choice or from the decision-making process that led to the purchase decision. This theoretical study examines the notion of regret arising simultaneously from both the product purchased and the decision-making process. A conceptual model is developed indicating two key moderators likely to impact the recognition and evaluation processes of the sources of regret.
\end{abstract}

The conceptualization of the regret emotion states that individuals experience discomfort when they contemplate, postpurchase, that a forgone alternative might have led to a better situation (Bell 1982; Loomes and Sugden 1982). For instance, a consumer may opt to purchase, for any given reason or reasons, a convertible instead of a sedan, or purchase a more expensive brand-name product over a lesser-known inexpensive product. Regret is experienced postpurchase from the product chosen (when one contemplates that the sedan or the lesser-known inexpensive brand might have been a better option) or from the decision-making process (when one contemplates that the process leading one to choose a convertible or the more expensive brand-name product might have been suboptimal).

Regret research in marketing literature has typically focused on the experience of the emotion arising from either the choice of the product purchased (e.g., Tsiros and Mittal 2000) or from the perspective of a decision action (e.g., Inman and Zeelenberg 2002). Given that regret results in a better assessment of postchoice valuation by consumers (Inman, Dyer, and Jia 1997), should outcomes be appraised only in terms of the product choice or the decision? As most decision actions are "deliberate conscious accomplishments" (Hastie and Dawes 2001, p. 26), it seems likely that they ought to be evaluated in terms of the determinants of what comprises a good decision-that is, how the decision is achieved and what is the result of the decision (Higgins

Neel Das (Ph.D., Louisiana State University), Assistant Professor of Marketing, Walker College of Business, Appalachian State University, Boone, NC, dasn@appstate.edu.

Anthony H. Kerr (Ph.D., Louisiana State University), Assistant Professor of Marketing, College of Business, Southeastern Louisiana University, Hammond, LA, anthony.kerr@selu.edu.
2000). We suggest that regret experienced by individuals is not solely a factor of the valence of the product choice (negative, when compared to a forgone product choice) or the valence of the decision-making process (negative, when compared to a forgone decision-making process) leading to the outcome. In other words, subsequent to an unfavorable outcome, regret experienced is a function of regret arising from both the chosen product (vis-à-vis the foregone product) and the decision-making process (vis-àvis the foregone decision-making process).

Herein lies the overarching contribution of this conceptual study. We put forward the notion that there are two sources of the regret emotion experienced-regret arising from the decision-making process and regret arising from the product (chosen as a result of the decision-making process). The decision-making process is regrettable when one realizes in hindsight that the process adopted was suboptimal. A suboptimal decision-making process occurs when, for instance, information search regarding alternatives is conducted less intensively. Intensive search for evaluating alternatives is one of the criteria determining the quality of a decision process (Janis and Mann 1977, cited in Pieters and Zeelenberg 2005, p. 18). Alternatively, the product purchased is regrettable when the consumer comes to know, postpurchase, about the existence of a better-performing product (compared to the chosen product) in the marketplace/space. The assumption, in terms of regret arising from the product purchased, is that a consumer does not knowingly forgo a better-performing product.

Both authors contributed equally to this paper and are listed alphabetically. 
We believe that such an investigation of the regret construct is likely to help researchers and practitioners better understand the emotion. Consumers do not always make correct attributions, subsequent to an unfavorable outcome. For instance, when the product purchased fails to perform, one may mistakenly blame one's decision-making process for such an unfavorable outcome, even though such a process leading to the purchase might have been optimal. On the other hand, when one adopts a suboptimal decisionmaking process, one may end up regretting the product purchased and blame the marketer thereof. Such misattributions are likely to shadow the functionality of the regret emotion, preventindividuals from properly regulating their regret, and may cause marketers to lose customers. Specifically, although regret makes one's mistakes more salient, it also helps to prevent one from making the same mistake in the future and acts as a catalyst to undo the cause of regret (Zeelenberg 1999). Such functionality from the negative emotion, however, can only be obtained when one makes correct attributions subsequent to the failure of the decision action. Following the experience of regret, individuals also try to perform behaviors that may ameliorate the feelings encountered (Zeelenberg and Pieters 2007); however, such behaviors can only be successful in blotting the pain if such individuals take the right actions based on the correct attributions. Finally, if marketers become aware of such misattributions on the part of the consumer, they may communicate and clarify the roles that consumers need to play in the consumption delivery and administration of a product (Soscia 2007).

In summary, in this conceptual research we ask and try to answer the following questions: Is it likely that when one is experiencing regret, there could indeed be two sources of the regret emotion occurring simultaneously and one may not be cognitively aware of such a distinction? Could there be situations where one may regret the product choice more than the decision-making process or vice versa? What could lead one to make a distinction between regret emanating from an unfavorable product choice and that from an unfavorable decision-making process? Finally, what might be some of the possible practical and managerial implications originating from the distinction between the two sources of regret?

\section{THE REGRET EMOTION}

Regret is a painful negative feeling arising as a consequence of decision making when one appears to have made a wrong decision, even if it appeared to be the right decision at the time it was made (Loomes and Sugden 1982). In other words, regret arises when one compares "what is" with "what might have been" (Sugden 1985) or when an individual realizes that the outcome of the rejected option might have been better (Zeelenberg 1999). Hence, an essential element of the regret emotion is the realization that a different choice would have led to a better outcome. Zeelenberg and Pieters further suggest that regret is a cognitive emotion, in that it "contains all the elements typical of emotional experiences" $(2007$, p. 6) such as a sinking feeling, thoughts about opportunities lost, and thoughts about mistakes made by one and the desire to correct them, if given a chance.

Given the definition of the regret emotion, how is it different from disappointment? Both regret and disappointment are experienced when there is disconfirmation between what has happened and what could have happened. In the case of regret, the comparison is between the perceived performance of the chosen option and the perceived performance of a foregone alternative, whereas for disappointment, the comparison is between the expectations and the perceived performance level of the one chosen alternative (Zeelenberg et al. 2000). In other words, the reference point for regret is external (encompassing both the chosen option and the foregone alternatives), whereas that for disappointment is internal (encompassing only the chosen option). It is also suggested that disappointment generally leaves one powerless with a tendency to want to get away from everything and not wanting to do or have any association with the outcome (Zeelenberg et al. 1998). Regret, on the other hand, involves feelings of responsibility and results in not being able to get away from such an experience.

\section{TWO SOURCES OF REGRET}

Given that regret is experienced as a result of a comparison between what is and what might have been, it seems likely that regret may arise as a result of an unfavorable decision-making process or an unfavorable product choice. The important notion to appreciate is that an unfavorable decision-making process is separate from an unfavorable product choice, and individuals may experience regret from either one or both. Below are three different scenarios to underline the notion of how regret may arise separately or in unison from the sources.

Scenario 1. Sugden (1985) puts forth the following vignette that shows regret may arise from the decision-making source, although the outcome is satisfactory: suppose one is inebriated after a party and decides to drive back home in an impaired condition. He or she does reach home safely. 
However, the next morning he or she starts to think of what might/could have happened while driving on his or her way back home. In this instance, the decision-making process involves the element of determining to drive back home in an intoxicated condition and the result of such a decision is the fact that the person reaches home (fortunately) without any untoward incident. Based on our definitions of a regrettable decision-making process and a regrettable product (outcome, in this scenario) as provided earlier, it seems evident that a decision choice to drink and drive is likely to be more regrettable rather than the fact of reaching home safely.

Scenario 2. Connolly and Zeelenberg (2002) illustrate a situation when the regret arises from the outcome, although the decision-making process is satisfactory. A decision to vaccinate one's child against a serious disease is likely to result in regret from the outcome when the child suffers a bad side effect. Although the decision to vaccinate might have been a carefully executed one, the outcome is regrettable. Here the decision-making process is likely to involve, among other things, elements such as researching carefully the pros and cons of the vaccination, securing a second (or even multiple) opinion(s) from experts, deciding on a good physician, and so on. The product received is the vaccination for the child. Assuming a prudent decision-making process, the product is likely to be regretted when the child suffers from the deleterious side effect.

Scenario 3. Consider a situation in which a consumer decides to buy a particular brand of a digital camera even though the salesperson recommends another brand. Subsequently, the individual comes across the ratings of Consumer Reports regarding the purchased brand and the recommended brand. Much to the consumer's dismay, the overall rating of the purchased brand is much lower than the recommended brand. The decision-making process now involves elements such as recognizing the correct need for the type of camera, deciding on a store to get the product from, identifying a competent salesperson, and assessing the information received, among other things. It is quite usual that individuals are likely to listen to experts (salesperson, in this case) in order to minimize risks (Grewal, Gotlieb, and Marmorstein 1994). The product received is the brand purchased (different from the recommendation of the salesperson). In such a situation, the consumer is likely to regret both his or her decision-making process (of not listening to the salesperson's recommendation) and the opportunity to own a better product.

The above scenarios attempt to underline the notion that the experience of regret may arise from the decision- making process, or from the product choice, or from the decision-making process and the product choice. Hence, an individual needs to be aware of the sources of regret in order to understand what has happened. A significant reason as to why one needs to understand the experience of the emotion is because of the functionality or learning mechanism associated with the emotion. Given the aversive and salient nature of the emotion (Zeelenberg 1999), individuals are likely to learn from their mistakes and alter their behavior in subsequent similar situations. However, if the individual does not correctly ascertain the source of regret, then the functionality of regret is likely to be absent.

As noted previously, extant regret research in marketing has primarily investigated the occurrence of regret arising from a product choice or from a decision-making perspective. There has been no investigation of the emotion arising from both the product choice as well as the decision-making process in the same study. Tsiros and Mittal (2000), for instance, studied the experience of regret arising from a product choice without taking into account the decisionmaking perspective. The results of their studies essentially showed that regret arises from the existence of a betterperforming foregone alternative. Inman and Zeelenberg (2002), on the other hand, studied regret emanating from a decision-making perspective, without looking at the performance of the product chosen. Specifically, they investigated regret arising from a decision to do things as they were done in the past (i.e., maintaining status quo) versus a decision to do things differently in the future (i.e., switch brands or stores). For instance, buying the same brand over subsequent purchase decisions versus switching to a new brand in a subsequent buying decision. The results from their study showed that, contrary to prior findings, when there is a justifiable reason for a switch to occur, maintaining status quo results in greater regret.

Researchers in psychology, however, have introduced the notion of the sources of regret in their domain. Pieters and Zeelenberg (2005) have looked at the sources of regret in the context of intention-behavior inconsistency. Their basic premise was that when individuals make a decision that was not originally intended, they are likely to regret that unintended decision, regardless of the outcome from such a decision. In a series of three different research contexts (a scenario approach, assessing autobiographical memories of regrettable events, and a longitudinal study relating to real-life voting in national elections), Pieters and Zeelenberg found that a bad inconsistent decision process amplified regret, independent of the outcome. We contend that if a conceptualization of regret, emanating 


\section{Figure 1 \\ Proposed Conceptual Model}

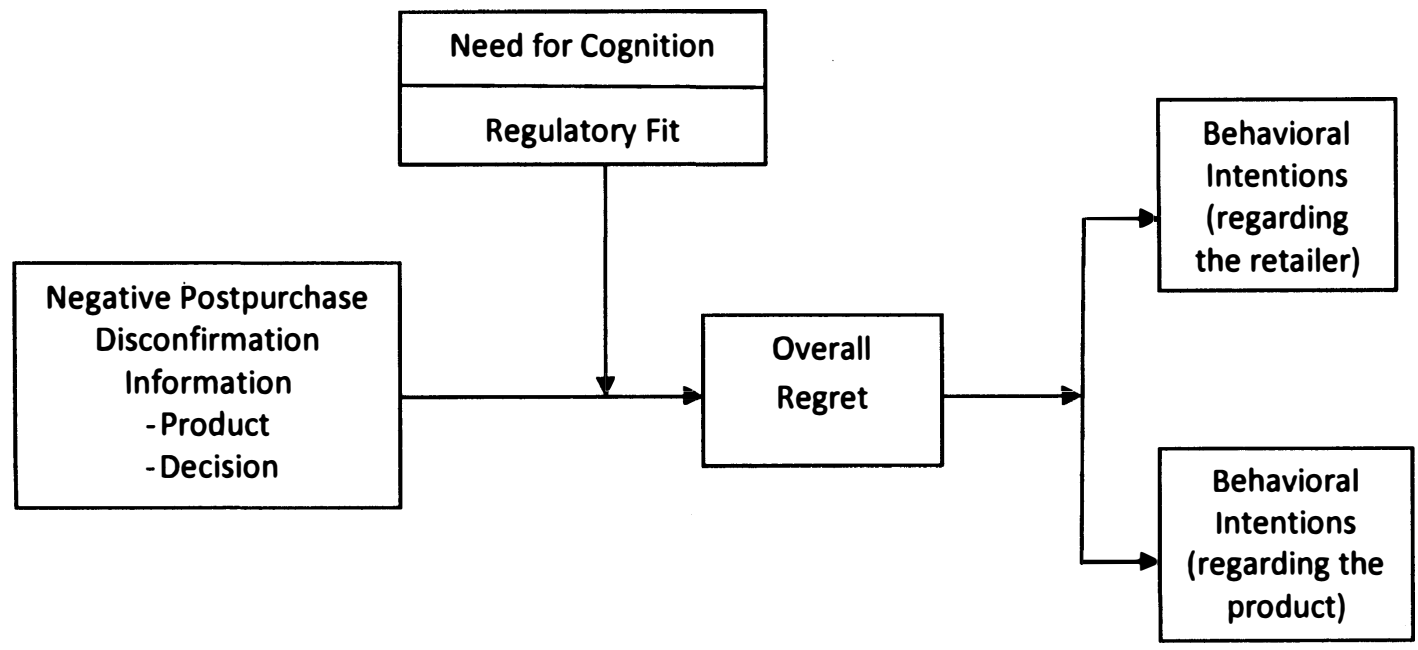

from both the product and the decision-making process, is introduced in the context of a consumer purchase decision, marketing researchers and practitioners alike are likely to better understand the phenomenon and the consequences of the same.

\section{CONCEPTUAL MODEL}

Figure 1 represents the conceptual model for the regret process discussed in this paper. Regret can arise from product choice or the decision-making process due to the diagnosticity of the negative postpurchase information regarding such source(s). In this study's context, diagnosticity refers to the negative postpurchase information receiving more weight when assessing or judging how an alternative foregone product option or the decision-making process might have resulted in a better outcome. However, not all individuals are likely to be motivated to process the negative postpurchase information regarding the sources separately, thereby disenabling them to distinguish between the sources of regret. The propensity to do so depends on the motivation of the consumer to think about what went wrong and how. Although several variables may indicate when consumers make the distinction between the sources of regret, we feel that two such variables need to be a part of this discussion-need for cognition and regulatory fit. Before we discuss the moderating effects of each, we present a short argument underlining the need for their inclusion in the present model.

As mentioned earlier, the experience of regret requires running a mental recreation of what happened and what could have happened and subsequently comparing the two. However, such simulations are only likely to be conducted when one enjoys and engages in such cognitive activities-the characteristic of need for cognition. Hence, it is necessary to include need for cognition as an integral part of this conceptual model. Regulatory fit, a goal-pursuit theory, aligns the relationship between motivation of the individual and the manner in which he or she engages in the goal; such fit dictates a preference for certain strategies (to accomplish the goal) (Cesario, Higgins, and Scholer 2008). Furthermore, there is a notion of "feeling right" when such strategies are used which are then transferred to subsequent evaluations (Avnet and Higgins 2006). For instance, prior research indicates that individuals place a higher monetary value to objects when their choice strategy fits their regulatory orientation as compared to when it does not (Avnet and Higgins 2006). In terms of this current research, when individuals are engaged in a decision-making process, they are likely to go through the process and consequently assess their decision making based on their regulatory orientations. Hence, it is necessary to include regulatory fit for a better understanding of our conceptual model. Next we discuss the moderating variables and their influence in detail.

\section{Need for Cognition}

Enjoyment of and motivation to engage in effortful cognitive information processing is conceptualized as an individual's need for cognition (Cacioppo and Petty 1982). Need for cognition is an important individual difference variable that determines variations in consumer evaluations. Past research has examined its effect, inter alia, on variations in 
consumer attitude (Areni, Ferrell, and Wilcox 2000; Martin, Lang, and Wong 2004; Underwood and Shaughnessy 1975), consumer involvement (Andrews, Durvasula, and Akhtar 1990), message framing (Zhang and Buda 1999), price acceptability (Suri and Monroe 2001), and mental accounting (Chatterjee et al. 2000).

In terms of this research effort, we intend to posit the effects of need for cognition in terms of evaluating a decision action and the resultant outcome. Any action relating to a decision may be viewed as a short-term perspective, beginning from the initiation of and ending at the completion of the decision-making process. Alternatively, actions relating to decisions can involve a long-term motivational perspective composed of four distinct sequential phases (Heckhausen and Gollwitzer 1986). The initial or predecisional phase involves the identification of different goals constituted of the various wants, needs, and desires of individuals. The second phase, or postdecisional phase, comes into effect when the individual makes a decision to engage in one of these goals and selects strategies regarding the implementation of the same. A transition is made to the third phase, or actional phase, whereby individuals act on the strategies identified in the previous, postdecisional phase. Upon reaching an outcome resulting from these strategies, individuals enter the postactional phase when they evaluate the outcome.

Extant research (Gollwitzer 1990; Gollwitzer and Kinney 1989) has posited that in effect, each phase motivates an individual to be tuned-in and ready for any given specific task necessary for the successful implementation of the same. For instance, the predecisional phase gears a person's mind toward the expected values of potential goals and hence the person is likely to spend time thinking about the potential attractiveness of the different goals. In the postdecisional phase, the person is more involved in the determination of the appropriate strategy to use to attain the chosen goal and, therefore, thinks in terms of when, where, and how. Similarly, in the final postactional phase, the person is more likely to think in terms of the results of the implemented strategy (completed during the actional phase) and determine whether the outcome achieves the desired goal as set forth in the initial or predecisional phase. If the goal is not achieved with the final outcome (derived in the postactional phase), then one is likely to ponder each of the different phases and try and find out what went wrong.

Using this past research as our basis, it is our contention that only highly involved consumers are likely to adopt a long-term motivational perspective in terms of decision making. In contrast, consumers with low involvement are likely to take a short-term decision-making perspective and not separate an action relating to a decision into separate phases. In other words, highly involved consumers are more likely to separate the source(s) of regret, whereas less-involved consumers would simply recognize that the regret emotion exists without distinguishing the particular source(s) of the emotion.

Furthermore, regret is viewed as a cognitive emotion. In order to understand whether one experiences regret or not, one has to involve him- or herself in a cognitive process (Landman 1993; Zeelenberg 1999). Hence, regret results in a sufficient degree of cognitive appraisal. In the context of this research, such a cognitive appraisal may be the means to understanding the cause(s) of regret experienced. Specifically, the distinction between the two types of regret is likely to be apparent for individuals with a high need for cognition. High need for cognition individuals have a greater tendency to think elaborately on relevant information, compared to low need for cognition individuals. The latter group consists of individuals who are usually cognitive misers (Tidwell, Sadowski, and Pate 2000). Whereas high need for cognition individuals think more actively about their options, low need for cognition individuals do not (Simon, Fagley, and Halleran 2004). In other words, those who are apt and more motivated to cognitively appraise a negatively disconfirmed transaction are more likely to attempt to decipher as to what and how something went wrong. On the other hand, those who are not likely to cognitively appraise a transaction, subsequently, are unlikely to attempt to decipher or identify any specific source of regret.

Based on the above discussion, we propose:

Proposition 1: Need for cognition will likely influence individual mental processing of negative postpurchase information. Specifically, high need for cognition individuals are more likely to separate the sources of regret experienced-that is, product versus decision-making process-than low need for cognition individuals.

\section{Regulatory Fit}

How individuals arrive at their desired goals depends on their unique orientations regarding how they make decisions (e.g., Aaker and Lee 2001; Higgins 1997, 2000). Such orientations may relate to the quest to acquire a positive outcome or to prevent a negative outcome. Regulatory focus theory (Higgins 1997) states that people have a promotion orientation when they try to acquire a positive outcome (e.g., Aaker and Lee 2001; Higgins 2000), and thereby maintain a sense of advancement and accomplishment 
(Roese, Hur, and Pennington 1999). On the other hand, people have a prevention orientation when they try and eschew a negative outcome (e.g., Aaker and Lee 2001) and hence garner more security and protection (Roese, Hur, and Pennington 1999).

Regulatory focus further identifies different ways and means of goal achievement. Eagerness means and vigilance means specify the achievement of goals under promotion and prevention orientations, respectively (Crowe and Higgins 1997; Higgins 2000, 2002). Eagerness refers to attempts to maximize the presence of positive outcomes and thereby guarantee aspiration and accomplishments, whereas vigilance refers to attempts to minimize the presence of negative outcomes and thereby ensure safety and protection (Higgins 2000; Higgins and Spiegel 2004). Therefore, promotion-oriented individuals use eagerness means, whereas prevention-oriented individuals use vigilance means to make decisions. For example, consider two recent business school graduates with high-paying jobs looking to buy a car. One considers a top-notch convertible in order to underline his or her accomplishments and status. The other considers a top-of-the-line minivan proven to be reliable and safe. Although both graduates demand the same product, their respective regulatory focus drives them to have "distinct patterns of attention, reasoning, and memory, possibly involving different neuroanatomical systems" (Gray 1994 quoted in Roese, Hur, and Pennington 1999, p. 1110) and subsequently resulting in different choices.

The important notion to understand is that no matter what the regulatory focus is for a certain individual, there is a sense of "feeling right" when decisions are made according to one's regulatory orientation (e.g., Aaker and Lee 2006; Cesario, Higgins, and Scholer 2008). This sense of "feeling right" emanates from situations involving a regulatory fit between an individual's existing orientation and the strategies used to make a choice. In other words, regulatory fit is experienced when an individual pursues a goal that sustains his or her regulatory orientation (Avnet and Higgins 2003). The fit emphasizes the fact that the individual used the correct strategy to make a choice and also increases the importance of his or her action (Higgins 2002). Overall, regulatory fit is likely to increase, and nonfit is likely to decrease, the value of a decision (Avnet and Higgins 2003). There are several implications of the occurrence of fit. Extant findings indicate that the presence of a fit results in, inter alia, an individual's willingness to pay more for a product, having a more positive attitude toward a product, and being more confident in one's judgment (Aaker and Lee 2006).
Wang and Lee (2006) mention certain boundary conditions for the fit effect. In their study, it was found that individuals do search for more information and spend more time processing information when they were otherwise not motivated to process such information. On the other hand, individuals who were otherwise highly motivated to process product information did not indicate any regulatory focus effect in the product evaluations. Perhaps the notion of a regulatory fit is used as a heuristic for making decisions when the involvement is low. When individuals are highly motivated to process product information, they are more likely to proceed along a systematic decision-making, information-gathering continuum, regardless of promotion or prevention concerns.

In the context of our current study, we utilize the concept of regulatory fit to further elucidate our conceptualization of the regret emotion. Given our definitions for a regrettable decision-making process and a product, we posit that when one's decision-making process is regrettable (solely or in conjunction with the product), regulatory fit is going to have an effect. Fit is not likely to play a role when the product is solely regrettable. Regulatory fit relates to one's decision and regulatory orientation, and "the regulatory fit value from how a decision is made is independent of the outcome value" (Avnet and Higgins 2003, p. 525, emphasis in original). This effect is also likely to be a function of the need for cognition. Evans and Petty (2003) concluded that need for cognition moderates the effects of regulatory fit. The results of their study indicate that individuals' evaluations of a product are affected by the message quality (weak versus strong arguments). This is especially prevalent when the message is framed with a promotionor prevention-focused appeal, but only in the case of low need for cognition individuals. In the case of high need for cognition individuals, evaluations of a product are affected by message quality (weak versus strong arguments), regardless of regulatory fit. Wang and Lee (2006) also found similar results while investigating the boundary conditions of regulatory fit, as stated in the above paragraph.

Based on the above discussion, we can conclude that high need for cognition individuals are not likely to be affected by regulatory fit when the postpurchase diagnostic information relates to either the product or both the product and the decision-making process. Low need for cognition individuals, on the other hand, are likely to be affected by regulatory fit when the postpurchase diagnostic information relates to either the product, the decision-making process, or both the product and the decision-making process. Hence, the following proposition is introduced: 
Proposition 2: Neither the presence nor absence of regulatory fit will likely affect to any significant degree the level at which an individual experiences postpurchase regret when the negative postpurchase disconfirmation information relates to only the product or to both the product and the decision-making process. In contrast, the presence or absence of regulatory fit will likely affect to a significant degree the level at which an individual experiences postpurchase regret when the postpurchase diagnostic information relates to only the decisionmaking process.

We further propose that need for cognition (in addition to the interactions posited above) is also going to have an effect on the regret experienced. We therefore propose the following interaction between the negative postpurchase disconfirmation information, need for cognition, and regulatory fit:

Proposition 3: The influence of the presence of regulatory fit on the degree to which one experiences postpurchase regret (relating only to the decision-making process) will likely differ among high need for cognition and low need for cognition individuals. Specifically, among high need for cognition individuals, neither the presence nor the absence of regulatory fit will likely significantly influence the degree to which one experiences postpurchase regret when the diagnostic information relates to only the decision-making process. In contrast, among low need for cognition individuals, the degree to which one experiences postpurchase regret will likely be lower (higher) when regulatory fit is present (absent) and when the diagnostic information relates to only the decisionmaking process.

\section{Attitude Toward the Retailer or the Product Purchased}

The model also indicates that the level of regret experienced will likely affect the attitude of individuals regarding the product purchased or the retailer. Attitudes that may be exhibited include, inter alia, intentions to switch and complaint about the product purchased or the retailer.

Switching refers to abandoning a relationship with a retailer or a manufacturer (of a particular product) and beginning a new relationship with a different retailer or manufacturer (Zeelenberg and Pieters 2004). Prior research suggests that switching is a direct response to regret; that is, the greater the regret, the more there is the tendency to switch (Zeelenberg and Pieters 2004) and, subsequently, lower the tendency toward repurchase intentions (Tsiros and Mittal 2000).

Kowalski (1996) describes consumer complaint behavior as behavioral expressions of dissatisfaction or unfavorable attitudes directed toward an individual, a situation, or an object. Using the disconfirmation paradigm as his basis, Kowalski expressed that complaint behavior reflects dissatisfaction from an exchange generated from a negative disconfirmation of expectancies. Extant regret research in marketing has found no effect of regret on consumer complaint intentions (Tsiros and Mittal 2000). Research has shown that although satisfaction affects complaint intentions, the effects of regret are mediated via satisfaction (Tsiros and Mittal 2000). Essentially, one may be satisfied with the product but may experience regret when a foregone alternative is perceived to perform better than the chosen product. In such a situation, it is not likely for one to complain to the manufacturer (of the chosen product) about another product that is perceived to outperform the chosen one. Switching to a better-performing product in the future is the likely outcome.

We suggest that when trying to understand the attitudes of the individual toward the product purchased or the retailer, the notion of responsibility for the decision action becomes a key issue. Responsibility is an important precondition for regret. The more responsible one feels for the decision action, the more regret one is likely to experience subsequent to an unfavorable result (Zeelenberg et al. 1998; 2000). Tsiros, Mittal, and Ross (2004) suggest that responsibility incorporates two aspects-who caused the failure and the amount of control one had over a decision. Hence, when one feels responsible for the unfavorable outcome, a sense of guilt may attenuate the intentions of switching and increase the same for repurchase intentions. On the other hand, when one feels less responsible for the unfavorable outcome, and if such an outcome is attributed to, say, a faulty recommendation from a salesperson (perceived to be an expert), one may express intentions to complain. While responsibility is likely to drive the feelings of regret, it may also help consumers adjust their behavioral intentions accordingly. Probable boundary conditions, vis-à-vis the extant research findings, may emerge as explained below.

When the decision-making process is regrettable, boundary conditions for switching and repurchase intentions may originate. Specifically, the attribution is likely to be internal (to the individual), and less unfavorable attitudes are likely to be formed toward the retailer or the product purchased. Corollarily, when one's decision is well thought out, but the product choice fails to deliver, one is likely to 
have unfavorable attitudes toward the product. Moreover, if the product choice was due to a salesperson's recommenda-tion (where listening to the salesperson was deemed to be a part of an optimal decision-making process), unfavorable attitude is also likely to be associated with the retailer. Spe-cifically, complaint intentions may be exhibited toward the retailer who recommended the suboptimal product. Finally, when both sources of regret are at work, both internal and external attributions are made for the unfavorable outcome. However, whether this situation will be any different from the one where regret is experienced due to an unfavorable product choice is debatable. We posit that when regret experienced is attributed primarily due to the unfavorable product choice, the attitude formation toward the retailer and the product is likely to be more negative than when regret is attributed to both one's decision-making process and the unfavorable product choice. In the former situa-tion, when one knows that he or she is not to be blamed for what has happened, one is likely to vent out more on the external party (i.e., product and retailer). Alternatively, in the latter situation, when regret is attributed to both one's decision-making process and the unfavorable product choice, then one could be relatively more forgiving toward the external party (i.e., product and retailer).

Given the discussion above, the following proposition is presented:

Proposition 4: Consumer attitudes toward the retailer and the product purchased will likely be more unfavorable when the negative postpurchase disconfirmation infor-mation pertains only to the product choice versus when the negative postpurchase disconfirmation information pertains to either the decision-making process or to both the product choice and the decision-making process.

\section{DISCUSSION}

Campbell Soup Company ran an advertisement for its V8 vegetable soup stating, "WOW, I could have had a V8." In doing so, the company probably tried to make their con-sumers realize that their decision to buy another brand would result in an unfavorable experience compared to the V8 brand. The point to note is that the company wanted the consumers to realize that their decision could have enabled them to get a better product. In other words, the headline in the advertisement probably acted as a catalyst for the consumers to think about the decision they made regarding the chosen product. This example underlines the key objective of this research.
The objective of this research was to initially introduce the notion of regret arising from two different sourcesthe decision-making process adopted and the product choice as a result of the decision-making process-and subsequently illustrate how individuals may misattribute the source of regret when both the sources of regret are measured. Although extant regret research in marketing has investigated regret arising from the product or from the decision-making source, no study has looked at the simultaneous assessment of the sources. Regret research in psychology has introduced the notion in their domain by examining decision inconsistency. In this research, we propose factors other than decision inconsistency in order to have the segregation of the sources of regret. Hence, if individuals understand what it is they are regretting when they experience the emotion, it will be helpful for them to regulate or ameliorate the feelings arising thereof.

By investigating the regret emotion in this way, we hope to add to the burgeoning field of regret-related and decision-making research. In terms of decision-making research, for instance, Zhang and Mittal (2005) looked into the effects of procedural and outcome accountability in the context of consumer decisions and found that under certain conditions, perceived decision difficulty is assuaged for procedural accountability and enhanced for decision accountability. Our current research tends to supplement this work in the realm of a postpurchase emotional context. Regret arising from the decision-making process may be looked upon as an outcome of procedural accountability, and that arising from the product choice a result of outcome accountability.

\section{THEORETICAL AND MANAGERIAL IMPLICATIONS}

The suggestions in this conceptual paper could have several implications for research and practice. By separating the experience of the regret construct as we proposed, it allows us to better understand its consequences or outcomes in a consumer decision context. In terms of behavioral intentions, Tsiros and Mittal (2000) found an inverse relationship between regret and repurchase intentions, and Zeelenberg and Pieters (2004) found a direct relationship with switching intentions. In other words, the greater the intensity of the regret experienced, the lesser the likelihood of repurchasing the product and the greater the likelihood of switching to a different product in the future. Neither Tsiros and Mittal (2000) nor Zeelenberg and Pieters (2004) found any effects of regret on complaint intentions. However, we propose a 
likely boundary condition to the above-mentioned findings. When the attribution for an unfavorable outcome is internal to the consumer (when one's decision-making process is the source of regret), the chances of exhibiting behavioral consequences, such as switching, are likely to be lower than when the attribution is external (product choice). Moreover, when the attribution is external, complaint intentions are also likely to arise because the consumer may want to talk about his or her bad experience to the retailer, company, or to others. Hence, behavioral intentions may not be affected as postulated by previous research when both sources of regret are examined.

Probable managerial implications that emanate from this discussion should focus on the reduction of negative consumer behavioral intentions possibly stemming from either one of the sources of postpurchase regret. Marketers may benefit if they can make the consumers' role more salient or participatory in the purchase, delivery, and consumption of a product. In such a way, attributions are facilitated so that consumers are not as likely to make misdirected attributions that would otherwise prove harmful or damaging to the marketer. For instance, some hotels allow self-registration for guests on their arrival, whereby a guest has the opportunity to select his or her room; while purchasing airline tickets online, a consumer has the opportunity to select his or her seat. In regard to averting misdirected attributions, the above examples depict participatory consumer involvement, whereby subsequent to a bad room choice by a hotel guest or a bad seat selection by a passenger, one can only blame him- or herself and not direct the blame externally to the marketer. On the flip side, when consumers do not experience regret from either their decision-making process or the product (say, when elation occurs), the segregation of the sources and its proper attribution may also help the generation of positive word-of-mouth regarding the product/retailer.

\section{FUTURE RESEARCH}

In addition to empirically testing the propositions developed and presented in this paper, future research efforts may also discover additional moderating influences that would help anticipate the effects of the two sources of regret on postpurchase behavior. A continuation of the study and analysis of the roles of attribution theory and complaint behavior, as they relate to regret behavior, would also be of interest. The opportunities to contribute to the regret stream of marketing literature, from refining and clarifying the sources of regret, to determining the behavioral impact that each source of regret may have on postpurchase attitudes and outcomes, are plentiful.

\section{CONCLUSION}

This conceptual presentation was developed and explored with the objective of explaining two sources of the postpurchase regret emotion arising simultaneously. The model introduced two key moderating influences believed to affect the cognitive recognition and evaluative processes of these sources of regret and their subsequent attitudinal effects on postpurchase behavioral outcomes. Future research possibilities emerging from this research include, inter alia, the empirical analysis of the propositions offered. Additional scrutiny regarding other moderating influences on the differentiation of the sources of regret is also likely to contribute to this area of consumer research.

\section{REFERENCES}

Aaker, Jennifer, and Angela Lee (2001), "I Seek Pleasures, We Avoid Pains: The Role of Self-Regulatory Goals in Information Processing and Persuasion," Journal of Consumer Research, 28 (June), 33-49.

- and - (2006), "Understanding Regulatory Fit," Journal of Marketing Research, 43 (February), 15-19.

Andrews, J. Craig, Srinivas Durvasula, and Syed H. Akhter (1990), "A Framework for Conceptualizing and Measuring the Involvement Construct in Advertising Research," Journal of Advertising, 19 (4), 27-41.

Areni, Charles S., M. Elizabeth Ferrell, and James B. Wilcox (2000), "The Persuasive Impact of Reported Opinions on Individuals Low vs. High in Need for Cognition: Rationalization vs. Biased Elaboration," Psychology \& Marketing, 17 (10), 855-887.

Avnet, Tamar, and E. Tory Higgins (2003), "Locomotion, Assessment, and Regulatory Fit: Value Transfer from 'How' to 'What,'" Journal of Experimental Social Psychology, 39 (September), 525-530.

- and - (2006), "How Regulatory Fit Affects Value in Consumer Choice and Opinions," Journal of Marketing Research, 43 (February), 1-10.

Bell, David E. (1982), "Regret in Decision Making Under Uncertainty," Operations Research, 30, 5 (September-October), 961-981.

Cacioppo, John T., and Richard E. Petty (1982), "The Need for Cognition," Journal of Personality and Social Psychology, 42 (January), 116-131.

Cesario, Joseph, E. Tory Higgins, and Abigail A. Scholer (2008), "Regulatory Fit and Persuasion: Basic Principles and Remaining Questions," Social and Personality Psychology Compass, 2 (1), 444-463.

Chatterjee, Subimal, Timothy B. Heath, Sandra J. Milberg, and Karen R. France (2000), "The Differential Processing of Price in Gains and Losses," Journal of Behavioral Decision Making, 13 (January), 61-75.

Connolly, Terry, and Marcel Zeelenberg (2002), "Regret in Deci- 
sion Making," Current Directions in Psychological Sciencè, 11 (6), 212-216.

Crowe, Ellen, and E. Tory Higgins (1997), "Regulatory Focus and Strategic Inclinations: Promotion and Prevention in Decision-Making," Organizational Behavior and Human Decision Processes, 69 (2), 117-132.

Evans, Lisa M., and Richard E. Petty (2003), "Self-Guide Framing and Persuasion: Responsibly Increasing Message Processing to Ideal Levels," Personality and Social Psychology Bulletin, 29 (3), 313-324.

Gollwitzer, Peter M. (1990), "Action Phases and Mind-Sets," in Handbook of Motivation and Cognition: Foundations of Social Behavior, vol. 2, E. Tory Higgins and Richard M. Sorrentino, eds., New York: Guilford Press, 53-92.

— Implemental Mind-Sets on Illusion of Control," Journal of Personality and Social Psychology, 56 (4), 531-542.

Grewal, Dhruv, Jerry Gotlieb, and Howard Marmorstein (1994), "The Moderating Effects of Message Framing and Source Credibility on the Price-Perceived Risk Relationship," Journal of Consumer Research, 21 (June), 145-153.

Hastie, Reid, and Robyn M. Dawes (2001), Rational Choice in an Uncertain World: The Psychology of Judgment and Decision Making, Thousand Oaks, CA: Sage.

Heckhausen, Heinz, and Peter M. Gollwitzer (1986), "Information Processing Before and After the Formation of an Intent," in In Memoriam Hermann Ebbinghaus: Symposium on the Structure and Function of Human Memory, Friedland Klix and Hermann Hagendorf, eds., Amsterdam: Elsevier/NorthHolland, 1071-1082.

Higgins, E. Tory (1997), "Beyond Pleasure and Pain," American Psychologist, 52 (December), 1280-1300.

(2000), "Making a Good Decision: Value from Fit," American Psychologist, 55 (November), 1217-1230.

_ (2002), "How Self-Regulation Creates Distinct Value: The Case of Promotion and Prevention Decision Making," Journal of Consumer Psychology, 12 (3), 177-191.

—_, and Scott Spiegel (2004), "Promotion and Prevention Strategies for Self-Regulation: A Motivated Cognition Perspective," in Handbook of Self-Regulation: Research, Theory and Applications, Roy F. Baumeister and Kathleen D. Vohs, eds., New York: Guilford Press, 171-187.

Inman, Jeffrey J., and Marcel Zeelenberg (2002), “Regret in Repeat Purchase Versus Switching Decisions: The Attenuating Role of Decision Justifiability," Journal of Consumer Research, 29 (June), 116-128.

—, James S. Dyer, and Jianmin Jia (1997), “A Generalized Utility Model of Disappointment and Regret Effects on Post-Choice Valuation," Marketing Science, 16 (2), 97-111.

Kowalski, Robin M. (1996), "Complaints and Complaining: Functions, Antecedents and Consequences," Psychological Bulletin, 119 (2), 179-196.

Landman, Janet (1993), Regret: The Persistence of the Possible, New York: Oxford University Press.

Loomes, Graham, and Robert Sugden (1982), "Regret Theory: An Alternative Theory of Rational Choice Under Uncertainty," Economic Journal, 92 (December), 805-824.

Martin, Brett, Bodo Lang, and Stephanie Wong (2004), "Conclusion Explicitness in Advertising: The Moderating Role of Need for Cognition and Argument Quality," Journal of Advertising, 32 (4), 57-65.
Pieters, Rik, and Marcel Zeelenberg (2005), “On Bad Decisions and Deciding Badly: When Intention-Behavior Inconsistency is Regrettable," Organizational Behavior and Human Decision Processes, 97 (1), 18-30.

Roese, Neal J., Taekyun Hur, and Ginger L. Pennington (1999), "Counterfactual Thinking and Regulatory Focus: Implications for Action Versus Inaction and Sufficiency Versus Necessity," Journal of Personality and Social Psychology, 77 (6), 1109-1120.

Simon, Andrew F., Nancy S. Fagley, and Jennifer G. Halleran (2004), "Decision Framing: Moderating Effects of Individual Differences and Cognitive Processing," Journal of Behavioral Decision Making, 17 (2), 77-93.

Soscia, Isabella (2007), "Gratitude, Delight, or Guilt: The Role of Consumers' Emotions in Predicting Postconsumption Behaviors," Psychology \& Marketing, 24 (10), 871-894.

Sugden, Robert (1985), "Regret, Recrimination and Rationality," Theory and Decision, 19 (1), 77-99.

Suri, Rajneesh, and Kent B. Monroe (2001), "The Effects of Need for Cognition and Trait Anxiety on Price Acceptability," Psychology \& Marketing, 18 (1), 21-42.

Tidwell, P.S., Cyril J. Sadowski, and Lia M. Pate (2000), "Relationships Between Need for Cognition, Knowledge, and Verbal Ability," Journal of Psychology, 134 (6), 634-644.

Tsiros, Michael, and Vikas Mittal (2000), "Regret: A Model of Its Antecedents and Consequences in Consumer Decision Making," Journal of Consumer Research, 26 (June), 401-417.

_, Vikas Mittal, and William T. Ross (2004), "The Role of Attribution in Customer Satisfaction: A Reexamination," Journal of Consumer Research, 31 (2), 476-483.

Underwood, Benton J., and John J. Shaughnessy (1975), Experimentation in Psychology, New York: Wiley.

Wang, Jing, and Angela Y. Lee (2006), "The Role of Regulatory Focus in Preference Construction," Journal of Marketing Research, 43 (1), 28-38.

Zeelenberg, Marcel (1999), "The Use of Crying Over Spilt Milk: A Note on the Rationality and Functionality of Regret," Philosophical Psychology, 12 (3), 325-340.

_- and Rik Pieters (2004), "Beyond Valence in Customer Dissatisfaction: A Review and New Findings on Behavioral Responses to Regret and Disappointment in Failed Services," Journal of Business Research, 57 (4), 445-455.

— of Consumer Psychology, 17 (1), 3-18.

- - Wilco W. van Dijk, Anthony S.R. Manstead, and Joop van der Pligt (2000), "On Bad Decisions and Disconfirmed Expectancies: The Psychology of Regret and Disappointment," Cognition and Emotion, 14 (4), 521-541.

- - - Joop van der Pligt, Anthony S.R. Manstead, Pepijn van Empelen, and Dimitri Reinderman (1998), "Emotional Reactions to the Outcomes of Decisions: The Role of Counterfactual Thought in the Experience of Regret and Disappointment," Organizational Behavior and Human Decision Processes, 75 (2), 117-141.

Zhang, Yinlong, and Vikas Mittal (2005), “Decision Difficulty: Effects of Procedural and Outcome Accountability," Journal of Consumer Research, 32 (3), 465-472.

Zhang, Yong, and Richard Buda (1999), "Moderating Effects of Need for Cognition and Responses to Positively Versus Negatively Framed Advertising Messages," Journal of Advertising, 28 (2), 1-16. 